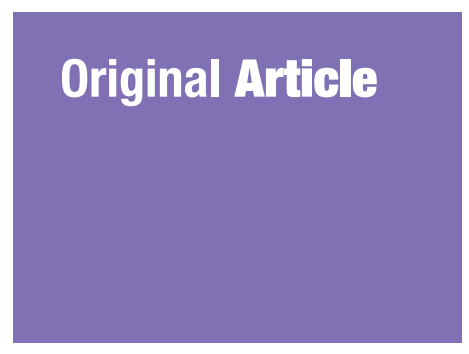

Submitted: 10 Oct 2019

Accepted: 8 Jan 2020

Online: 27 Feb 2020

\section{Risk Factors and Psychosocial Correlates of Emotionally Negative Dreams in Patients Referred to a Cardiac Rehabilitation Centre}

\author{
Mozhgan SAEIDI ${ }^{1}$, Ali Soroush ${ }^{2}$, Parvin Golafroozi ${ }^{1}$, Ali ZaKIEI ${ }^{3}$, \\ Behrooz FaridmaRANDI ${ }^{4}$, Saeid KomasI ${ }^{5}$
}
1 Cardiac Rehabilitation Center, Imam Ali Hospital, Kermanshah University of Medical Sciences, Kermanshah, Iran
2 Lifestyle Modification Research Center, Imam Reza Hospital, Kermanshah University of Medical Sciences, Kermanshah, Iran
3 Sleep Disorders Research Center, Kermanshah University of Medical Sciences, Kermanshah, Iran
4 Department of Psychology, Islamic Azad University, Kermanshah, Iran
5 Clinical Research Development Center, Imam Reza Hospital, Kermanshah University of Medical Sciences, Kermanshah, Iran

To cite this article: Saeidi M, Soroush A, Golafroozi P, Zakiei A, Faridmarandi B, Komasi S. Risk factors and psychosocial correlates of emotionally negative dreams in patients referred to a cardiac rehabilitation centre. Malays J Med Sci. 2020;27(1):97-105. https://doi.org/10.21315/mjms2020.27.1.10

To link to this article: https://doi.org/10.21315/mjms2020.27.1.10

\begin{abstract}
Introduction: Dream, as a kind of mental activity, includes various functions such as mood regulation, adjustment and integration of new information with the available memory system. The study was done for assessing the relationship between physiological and psychological components of cardiac diseases with emotionally negative dreams in cardiac rehabilitation.

Methods: At the baseline of this cross-sectional study, 156 patients from Western Iran participated during April-November 2016. People 20 years-80 years able to recall the emotional content of dreams after cardiac surgery entered the study. The Beck depression inventory (BDI), Beck anxiety inventory (BAI), Buss and Perry's aggression questionnaire (BPAQ) and Schredl's dream emotions manual were used for collecting data. A binary logistic regression analysis used for the study of the relationship between risk factors and emotionally negative dreams.

Results: The mean age of participants was $59(\mathrm{SD}=9)$ years (men: 64.1\%). The results showed that $25 \%$ of patients have negative emotional content. After adjustment for demographic variables, the results showed that increased anxiety [adjusted odds ratio (adj OR) $=1.08$ [1.011.16], $P=0.020]$ and anger $(\operatorname{adj} O R=1.03[1.00-1.06], P=0.024)$ and hypertension $(\operatorname{adj} O R=2.71$ $[1.10-6.68], P=0.030)$ can predict the dreams with negative content significantly.

Conclusion: The increasing rates of anxiety and anger and history of hypertension are related to increasing dreams with the negative emotional load. The control of risk factors of dreams with negative emotional load can be the target of future interventions.
\end{abstract}

Keywords: anger, anxiety, cardiovascular disease, depression, dream, risk factors

\section{Introduction}

Dream, as a kind of mental activity that occurs during sleep (1), includes various functions such as mood regulation, adjustment, and integration of new information with the available memory system (2). Some theories suggest that physiological factors are the base of a dream and dreaming is fundamentally physiological driven (3). Mutually, other views believe that the role of psychological and behavioral factors is more important 
$(2,4,5)$. These theories suggest that the content of a dream is concluded from cognitions and behaviour during the waking time $(1,5)$. So, dream probably has a role in the explanation of etiology and psychopathology in many psychiatric disorders (2, 4). For example, previous studies referred to the relationship between mood disorders such as depression (4), anxiety disorders (6) and alexithymia (7) with the contents of a dream.

The tensions during awaking time and occupational and social challenges through decreasing positive mood can lead to distressing sleep and annoying dreams $(2,8)$. For example, patients with cardiovascular problems usually experience high psychological distress because of death risk and invasive treatment procedures (9). Cardiac disease is concerned as a trigger to occur anxiety and depression or related disorders such as post-traumatic stress disorder (PTSD) (10-12). Anxiety disorders and depressed mood may be associated with negative dreams during sleep $(4,8)$.

Dreams have diagnostic and prognostic value and importance for therapeutic evaluation and assessment of psychiatric disorders, especially in mood disorders. The quantity and quality of dreams in patients with mood problems may predict remission from depression, response to antidepressants, and suicidal ideation and attempts (4). Thus, it seems that the assessment of dreams and their mechanisms and functions may help to percept cognitions, emotions, and complex behaviours in patients (2). Especially, in patients with cardiovascular problems, a study of dream mechanisms may help specialists predict the triggers and consequences of the illness (13).

Recent studies although have examined the relationship between dream and psychological and physical well-being included depression, insomnia, fatigue and other factors such as sex, age, the use of antidepressants or hypnotics and frequent heavy use of alcohol, cardiac symptoms among general population $(14,15)$, less focused on the population with cardiovascular problems (13). Thus, it seems that spontaneous study on physiological and psychological factors can facilitate the perception of complex mechanisms of the dream. We assume that both psychological and non-psychological factors influence the content of dreams, especially in patients with cardiovascular problems. The results of the current study will help to resolve the struggle and disputes of previous theories and studies
(2-5). So, the present study aimed to assess the physiological and psychosocial correlates of dreams with negative emotional content in patients referred to cardiac rehabilitation (CR) centre.

\section{Methods}

\section{Design and Context}

This cross-sectional study conducted in the CR department of Imam Ali hospital of Kermanshah (Western part of Iran) during April 2016 to November 2016. The statistical population concluded all coronary artery bypass graft (CABG) and valve replacement patients who participated in the $\mathrm{CR}$ programme.

\section{Sample, Sampling and Sample Size}

Firstly, using consecutive sampling, 194 patients participated in CR were selected. Then, 156 cases remained after screening the patients by inclusion criteria. Inclusion criteria include fluency in Farsi language, aged 20 years-8o years, ability to recall and report the emotional content of dream after cardiac surgery, and a tendency to participate. The reasons for excluding patients were: people with inappropriate age range $(n=5)$, because of their inability to remember dreams $(n=31)$, and unwillingness to participate $(n=2)$. According to formula $(n>50+8 \mathrm{~m})$ and 10 predictor variables in this study, the sample size of more than 130 cases seems appropriate (16). Informed consent was obtained from all individual patients included in the study. Also, all procedures performed in the study were following the ethical standards of the institutional research committee and with the 1964 Helsinki declaration.

\section{Procedure}

The steps of research were as follows: at first, the patients with criteria were identified by the research team and they were entered after written consent form and insurance for confidential identity. One week before the first session of exercise, demographic data (age, sex and education level), clinical data (anxiety, depression, anger and emotional content of dream) and medical data were recorded and collected by a clinical psychologist and a cardiologist of CR team. Beck depression and anxiety inventories, anger subscale of Buss and Perry's aggression questionnaire and Schredl's dream emotions manual provided to the 
patients by the psychologist and they fulfilled them individually after receiving necessary explanations. Also, the cardiologist recorded the data related to smoking, hypertension, diabetes mellitus, hyperlipidemia and family history of cardiac disease after an interview and assessment of patients' medical histories.

\section{Instruments}

\section{Socio-demographics and risk factors}

The samples self-reported their age, sex and current educational level in three categories: under diploma, diploma and academic degree. Also, self-reported family history of cardiac disease, smoking, hypertension, diabetes mellitus and hyperlipidemia was checked by the cardiologist.

\section{The Beck anxiety inventory (BAI)}

The scale is a 21-item exam of 3 scores for each item. The score of this questionnaire is varied from 0 to 63 . The final score includes 4 levels of anxiety: i) score $0-7$ is equal to no anxiety; ii) score 8-15 is equal to mild anxiety; iii) score $16-25$ is equal to moderate anxiety; and iv) score 26-63 is equal to severe anxiety. Cronbach's alpha of the inventory is 0.92 , the credential using the retest method with a oneweek interval is 0.75 and the consistency of the items is varied from 0.30 to 0.76 . Validity types of this scale have also been confirmed (17). The reliability and validity of this tool have been confirmed in the Iranian population (18).

\section{The Beck depression inventory (BDI)}

The inventory is a 21 items exam of 3 scores for each item. The score of this questionnaire is varied from 0 to 63. Interpreting the results is determined as 5 levels: i) $\mathrm{O}-4$ means possible denial; ii) $5-9$ is equal to very mild depression; iii) $10-18$ is equal to mild to moderate depression; iv) 19-29 means moderate to severe depression, and v) 30-63 shows that the patients suffer from severe depression. Beck et al. (19) discovered the retest reliability in a one-week interval as 0.93 . The reliability and validity of this tool have been confirmed in the Iranian population (20).

\section{Buss and Perry's aggression questionnaire (BPAQ)}

It is a 29-item questionnaire where participants rank certain statements along with a 5-point continuum from 'extremely uncharacteristic of me' to 'extremely characteristic of me.' The scale has four subscales includes anger, hostility, and verbal and physical aggression. The scores are normalised on a scale of $0-1$, with 1 being the highest level of aggression (21). Retest reliability of the scale in the Iranian population is 0.78 . Also, the instrument validity was approved by factor analysis (22). In the current study, we used only anger subscale to assess patients. The subscale included 7 items (1-9-12-18-19-23-28) and the sum score is ranged 7-35. Buss and Perry have report Cronbach's alpha of the anger subscale $0.83(21)$.

\section{Schredl's dream emotions manual}

This scale involves a dream with any positive or negative emotion (23). The emotional content intensity (both positive and negative emotions) is graded using the Likert spectrum in the 4-point category scale including none $=$ 1 , mild $=2$, moderate $=3$, or strong positive or negative emotions $=4$. Inter-rater reliabilities for these scales in previous studies were 0.82 for negative emotions and 0.64 for positive emotions (24). In the current study, the patients divided into two groups: i) those who's negative dream score is higher than a positive dream $=1$ and ii) those who's positive dream score is higher than a negative dream $=0$.

\section{Data Analysis}

The data related to sex, education level, family history of cardiac disease, smoking, hypertension, diabetes mellitus, hyperlipidemia and emotional content of dream were reported in a percentage format while data related to age, anxiety, depression, and anger were reported in a format of mean and standard deviation (SD). At baseline, Chi-squared and independent $t$-test were used to compare non-continuous and continuous between two groups. The binary logistic regression analysis was used to assess the relationship between all continuous and discontinuous components with the negative emotional content of the dream after an approved lack of roll-out from needed statistical pre-assumptions (16). Two models were designed and run, separately. In models 1 and 2, an adjustment was done for age $\times$ sex and for age $\times \operatorname{sex} \times$ education level, respectively. Hosmer-Lemeshow test used to evaluate the goodness of fit for logistic regression models. The Wald parameter was also reported. Analysis conducted by SPSS2O (IBM Corporation, Armonk NY, USA) for Windows and the level of significance was set at alpha $<0.05$. 


\section{Results}

\section{Baseline Risk Factors and Psychosocial Components}

Among the total 156 patients (64.1\% male) who participated in the study, 39 patients (25\%) had emotionally negative dreams. The risk factors and psychosocial characteristics of samples are presented generally and separately in Table 1. It can be seen from the table that there is a difference between the two groups in terms of anxiety, anger and hypertension. This means that anxiety and anger patients and people with hypertension history have significantly more negative dreams $(P<0.05)$, when compared to other patients,

\section{The Binary Logistic Regression Model}

Hosmer-Lemeshow test indicated that the fit of the model is appropriate $(P=0.414)$ and our model correctly predicts $75 \%$ membership of the group. Overall, the model was statistically significant $(P=0.012)$. Indicators of effect size demonstrated suitable explanatory power concerning negative dreams. Therefore, it suggests that our model can explain 16\%-23.7\% variance of negative dreams. The adjusted odds ratio (adj OR), 95\% confidence interval (CI) and $P$-value for each covariate are presented in Table 2. Concerning the logistic regression model, the four variables were found to be independently and significantly associated with negative dreams. According to the results, academic education level $(\mathrm{OR}=0.25$ [0.06o.99], Wald $=3.868, P=0.049)$, anxiety $(\mathrm{OR}=$ 1.08 [1.01-1.15], Wald $=4.822, P=0.028)$, anger $(\mathrm{OR}=1.03[1.00-1.06]$, Wald $=3.961, P=$ 0.047) and hypertension (OR = 2.52 [1.05-6.02], Wald $=4.329, P=0.037$ ) have more possibility of predicting negative dreams when compared to others.

In Table 3, adjustment for demographic variables (age, sex, and education level) was conducted and the significance of every variable was assessed in two models. In Model 1, after adjustment for age and sex, it was indicated that education level, anxiety and anger can predict negative dreams $(P<0.05)$. In Model 2, after adjustment for age, sex and education, it was indicated that only anxiety (adj OR $=1.08$ [1.01-1.16], $P=0.020$ ) and anger (adj OR = 1.03 [1.00-1.06], $P=0.024$ ) and hypertension (adj $\mathrm{OR}=2.71[1.10-6.68], P=0.030)$ can predict

Table 1. Baseline risk factors and psychosocial characteristics in the overall population and in those with negative and positive dream

\begin{tabular}{|c|c|c|c|c|}
\hline Variables & $\begin{array}{l}\text { Overall population } \\
\qquad N=156\end{array}$ & $\begin{array}{c}\text { Negative dream } \\
n=39(25 \%)\end{array}$ & $\begin{array}{c}\text { Positive dream } \\
n=117(75 \%)\end{array}$ & $P$-value \\
\hline $\operatorname{Sex}(\%)^{a}$ & & & & 0.441 \\
\hline $\begin{array}{l}\text { Male } \\
\text { Female }\end{array}$ & $\begin{array}{l}100(64.1) \\
56(35.9)\end{array}$ & $\begin{array}{l}23(59.0) \\
16(41.0)\end{array}$ & $\begin{array}{l}77(65.8) \\
40(34.2)\end{array}$ & \\
\hline Age, Mean (SD) ${ }^{b}$ & $59.1(9.0)$ & $61.1(7.8)$ & $58.5(9.2)$ & 0.112 \\
\hline $\begin{array}{l}\text { Education degree (\%) a } \\
\text { Under diploma } \\
\text { Diploma } \\
\text { Academic level }\end{array}$ & $\begin{array}{l}95(60.9) \\
31(19.9) \\
30(19.2)\end{array}$ & $\begin{array}{l}28(71.8) \\
7(17.9) \\
4(10.3)\end{array}$ & $\begin{array}{l}67(57.3) \\
24(20.5) \\
26(22.2)\end{array}$ & 0.193 \\
\hline \multicolumn{5}{|c|}{ Psychological factors, mean (SD) ${ }^{\mathrm{b}}$} \\
\hline $\begin{array}{l}\text { Anxiety } \\
\text { Depression } \\
\text { Anger }\end{array}$ & $\begin{array}{l}32.72(9.10) \\
16.24(3.91) \\
63.14(18.91)\end{array}$ & $\begin{array}{l}35.84(6.71) \\
16.49(3.23) \\
68.43(19.43)\end{array}$ & $\begin{array}{l}31.46(9.68) \\
16.14(4.20) \\
60.74(18.19)\end{array}$ & $\begin{array}{l}\text { 0.010 } \\
0.635 \\
\mathbf{0 . 0 2 7}\end{array}$ \\
\hline \multicolumn{5}{|l|}{ Risk factors (\%) a } \\
\hline $\begin{array}{l}\text { Diabetes } \\
\text { Hypertension } \\
\text { Hyperlipidemia } \\
\text { Family history } \\
\text { Smoking }\end{array}$ & $\begin{array}{l}32(20.5) \\
63(40.4) \\
45(28.8) \\
90(57.7) \\
63(40.4)\end{array}$ & $\begin{array}{l}6(15.4) \\
22(56.4) \\
12(30.8) \\
19(48.7) \\
13(33.3)\end{array}$ & $\begin{array}{l}33(22.2) \\
41(35.0) \\
33(28.2) \\
71(60.7) \\
50(42.7)\end{array}$ & $\begin{array}{l}0.360 \\
0.019 \\
0.760 \\
0.190 \\
0.462\end{array}$ \\
\hline
\end{tabular}

Notes: Significant difference between patients with positive and negative dream for each character is as: ${ }^{*}<<0.05$ $\mathrm{a}=$ Chi-squared test $\mathrm{b}=t$-test 
negative dreams. Specifically, the factors can increase the negative dreams at about 1.08, 1.03 and 2.71 times, respectively.

\section{Discussion}

The present study aimed to assess the physiological and psychological correlates of dreams with negative emotional content in patients with cardiovascular problems. The results showed that $25 \%$ of patients have negative emotional content. Hartman suggested that dreams are reflexes of life emotions during awaking time (25) and if one emotion is experienced more severe there is more possibility that it will occur in the dream (26). Patients with cardiovascular problems experience different emotions and challenges after confronting with disease and cardiac surgery (27). On the other hand, these patients usually act poorly in strategies of cognitive emotion regulation in awaking time (28). So, it seems that sleep time is the most appropriate time to regulate emotions. According to the model of the function of emotional regulation of dream, if patients experience the negative experiences in awaking time as negative emotions in a dream, they can deal with these emotions more easily $(29,30)$.

Table 2. Correlates of negative dream in the overall population (univariate model)

\begin{tabular}{|c|c|c|c|c|}
\hline Variables & $\begin{array}{c}\text { Negative dream } \\
(\%)\end{array}$ & Odds ratio (OR) & Wald & P-value \\
\hline \multicolumn{5}{|l|}{$\operatorname{Sex}(\%)$} \\
\hline $\begin{array}{l}\text { Male } \\
\text { Female }\end{array}$ & $\begin{array}{l}23.0 \\
28.6\end{array}$ & $\begin{array}{l}\text { Referent } \\
1.21(0.43-3.44)\end{array}$ & 0.131 & 0.718 \\
\hline Age $(\mathrm{M} \pm \mathrm{SD})$ & - & $1.03(0.98-1.09)$ & 1.317 & 0.251 \\
\hline \multicolumn{5}{|l|}{ Education level (\%) } \\
\hline $\begin{array}{l}\text { Under diploma } \\
\text { Diploma } \\
\text { Academic level }\end{array}$ & $\begin{array}{l}29.5 \\
22.6 \\
13.3\end{array}$ & $\begin{array}{l}\text { Referent } \\
0.86(0.30-2.51) \\
0.25(0.06-0.99)\end{array}$ & $\begin{array}{l}0.077 \\
3.868\end{array}$ & $\begin{array}{l}0.782 \\
0.049\end{array}$ \\
\hline \multicolumn{5}{|c|}{ Psychological factors $(\mathrm{M} \pm \mathrm{SD})$} \\
\hline $\begin{array}{l}\text { Anxiety } \\
\text { Depression } \\
\text { Anger }\end{array}$ & $\begin{array}{l}- \\
- \\
-\end{array}$ & $\begin{array}{l}1.08(1.01-1.15) \\
0.89(0.76-1.05) \\
1.03(1.00-1.06)\end{array}$ & $\begin{array}{l}4.822 \\
1.903 \\
3.961\end{array}$ & $\begin{array}{l}\text { 0.028 } \\
0.168 \\
\mathbf{0 . 0 4 7}\end{array}$ \\
\hline \multicolumn{5}{|l|}{ Risk factors (\%) } \\
\hline $\begin{array}{l}\text { Diabetes } \\
\text { Hypertension } \\
\text { Hyperlipidemia } \\
\text { Family history } \\
\text { Smoking }\end{array}$ & $\begin{array}{l}18.7 \\
34.9 \\
26.7 \\
21.1 \\
20.6\end{array}$ & $\begin{array}{l}0.74(0.25-2.15) \\
2.52(1.05-6.02) \\
1.04(0.40-2.69) \\
0.62(0.27-1.43) \\
0.72(0.29-1.83)\end{array}$ & $\begin{array}{l}0.313 \\
4.329 \\
0.007 \\
1.279 \\
0.469\end{array}$ & $\begin{array}{l}0.576 \\
\mathbf{o . 0 3 7} \\
0.933 \\
0.258 \\
0.494\end{array}$ \\
\hline
\end{tabular}

Notes: The risk factors and psychosocial characteristics listed in this table were all included as covariates in the generation of the binary logistic regression model

Statistically significant odds ratio for each character is ${ }^{*} P<0.05$

Table 3. Correlates of negative dream after adjusted for demographics

\begin{tabular}{llcccccccc}
\multirow{2}{*}{ Variables } & \multicolumn{4}{c}{ Model 1 } & \multicolumn{4}{c}{ Model 2 } \\
\cline { 2 - 10 } Education & adj OR & $\mathbf{9 5 \%}$ CI & Wald & P-value & adj OR & 95\% CI & Wald & $P$-value \\
Anxiety & 0.24 & $0.06-0.96$ & 4.043 & $\mathbf{0 . 0 4 4}$ & 4.48 & $0.31-64.12$ & 1.223 & 0.269 \\
Anger & 1.08 & $1.01-1.15$ & 5.120 & $\mathbf{0 . 0 2 4}$ & 1.08 & $1.01-1.16$ & 5.420 & $\mathbf{0 . 0 2 0}$ \\
Hypertension & 1.03 & $1.00-1.06$ & 3.762 & $\mathbf{0 . 0 4 7}$ & 1.03 & $1.00-1.06$ & 5.116 & $\mathbf{0 . 0 2 4}$ \\
\hline
\end{tabular}

Notes: Model 1: adjusted for age and sex. Model 2: adjusted for age, sex and education level 
Another finding suggested that increased anxiety and anger and hypertension are related to the negative content. In the present study, the mean score of anger and anxiety is higher than the normal level in almost of patients. Regarding the previous reports which indicated that there is a relationship between psychological disorders and emotional content of the dream $(4,6,7)$, it is suggested that negative emotional content of dream probably is a reflex of the developmental process of the psychopathology of psychiatric disorders such as anxiety and anger after diagnosis of cardiac disease (4, 6). Obviously, psychological and psychiatric symptoms manifest in patients after stabilised cardiac disease and regarding poor strategies of emotional regulation (28), the dreams with negative emotional content are responsible for emotional regulation (29). Despite this issue, lack of early treatment of anger and anxiety after a cardiac event may disrupt the quality of sleep $(31,32)$ so the possibility of emotional regulation will be destroyed even during sleep.

Finally, we can refer to the relationship between psychiatric disorders such as anger and anxiety with hypertension in the relationship between hypertension and negative dreams (33). The results of the previous studies indicate that inappropriate sleep quality, impulsivity, trait anxiety and dream anxiety are more in patients with hypertension compared to healthy controls $(33,34)$. Also, anxiety and anger inducedarousal can predict hypertension in a long-time $(35,36)$. So, regarding that arousal mechanism of these psychiatric components is related to hypertension in patients with cardiovascular problems, the relationship between hypertension and negative emotional content is possible.

It is noteworthy that the present results did not confirm the relationship between depression and negative emotional content. This finding is consistent with the results of a recent study by Komasi et al. (13). The findings of these researchers showed that depression alone not able to explain the negative content of dreams (13). This may be due to depression or taking antidepressants (37). Another study (38) points out that failure in recalling dreams is characterised by small EEG shifts from sleep to wakefulness in patients with depression.

The spectrum of cardiovascular diseases and interventions is very wide, including myocardial infarction (MI), coronary artery disease (CAD), chronic heart failure (VHF), pectoris angina, $\mathrm{CABG}$, heart valve replacement, percutaneous coronary intervention (PCI), etc. However, in the current study, only patients undergoing $\mathrm{CABG}$ or heart valve replacement referred to the $\mathrm{CR}$ were included in the assessment. Also, data were collected only from one intervention centre using consecutive sampling resulted from the small size of the statistical population. These limitations can lead to biased results (39). So, for future studies, we recommend a selection of randomly large sample in several centres across the country.

\section{Conclusion}

The increasing rates of anxiety and anger and history of hypertension are related to increasing dreams with negative and annoying emotional load in patients with cardiovascular problems. Although negative dreams may be effective in patients' emotional regulation after stabilising cardiac disease, control and early treatment of psychiatric disorders and cardiac risk factors especially hypertension are concerned as necessities of secondary prevention.

\section{Acknowledgements}

The authors appreciated the staff of Clinical Research Development Center of Imam Reza Hospital (Kermanshah University of Medical Sciences) for their collaboration in preparing this project. The authors also thank all participants.

\section{Ethics of Study}

This study was approved by the Ethics Committee of Kermanshah University of Medical Sciences (IR.KUMS.REC.1397.267) based on the Declaration of Helsinki.

\section{Conflicts of Interest}

None.

\section{Funds}

This study was funded by Kermanshah University of Medical Sciences (ID: 97334). 


\section{Authors' Contributions}

Conception and design: MS, AS, AZ, SK

Analysis and interpretation of the data: AZ

Drafting of the article: SK

Critical revision of the article for important

intellectual content: MS, AS

Final approval of the article: MS, AS, PG, AZ, BF, SK

Provision of study materials or patients: MS, SK

Statistical expertise: SK

Obtaining of funding: SK

Collection and assembly of data: PG, BF

\section{Correspondence}

\section{Mr Saeid Komasi}

$\mathrm{PhD}$ candidate in Neuroscience Research

(Kurdistan University of Medical Sciences, Iran)

Department of Psychology,

Clinical Research Development Center,

Imam Reza Hospital,

Kermanshah University of Medical Sciences,

Zakarya Razi Boulevard, Kermanshah, Iran.

Tel: +988334276299

Fax: +988334276299

E-mail: s_komasi63@yahoo.com

\section{References}

1. Schredl M. Dreams in patients with sleep disorders. Sleep Med Rev. 2009;13(3):215-221. https://doi.org/10.1016/j.smrv.2008.06.002

2. Aargn MY, Kara H, Bilici M, Savailli A, Telci M, Semiz MB, et al. The Van dream anxiety scale: a subjective measure of dream anxiety in nightmare sufferers. Sleep Hypnosis. 1999;4:204-211.

3. Hobson JA, McCarley RW. The brain as a dream state generator: an activation synthesis hypothesis of the dream process. Am $J$ Psychiatry. 1977;134(12):1335-1348. https:// doi.org/10.1176/ajp.134.12.1335

4. Palagini L, Rosenlicht N. Sleep, dreaming, and mental health: a review of historical and neurobiological perspectives. Sleep Med Rev. 2011;15(3):179-186. https://doi.org/10.1016/j. smrv.2010.07.003

5. Meaidi A, Jennum P, Ptito M, Kupers R. The sensory construction of dreams and nightmare frequency in congenitally blind and late blind individuals. Sleep Med. 2014;15(5):586-595. https://doi.org/10.1016/j.sleep.2013.12.008
6. Wittmann L, Schredl M, Kramer M. Dreaming in posttraumatic stress disorder: a critical review of phenomenology, psychophysiology and treatment. Psychother Psychosom. 2007;76(1):25-39. https://doi.org/10.1159/000096362

7. Lumley MA, Bazydlo RA. The relationship of alexithymia characteristics to dreaming. $J$ Psychosom Res. 2000;48(6):561-567. https:// doi.org/10.1016/Soo22-3999(00)ooo96-9

8. Barrett D, Loeffler M. Comparison of dream content of depressed vs nondepressed dreamers. Psychol Rep. 1992;70(2):403-406. https://doi. org/10.2466/pro.1992.70.2.403

9. Saeidi M, Komasi S, Heydarpour B, Momeni $\mathrm{K}$, Zakiei A. Those who perceive their disease as a physiological or psychological risk factor experience more anxiety at the beginning of the cardiac rehabilitation program. Res Cardiovasc Med. 2016;5(4):e29291. https://doi.org/10.5812/ cardiovascmed.29291

10. Saeidi M, Komasi S, Heydarpour B, Karim H, Nalini M, Ezzati P. Predictors of clinical anxiety aggravation at the end of a cardiac rehabilitation program. Res Cardiovasc Med. 2016;5(1):e30091. https://doi.org/10.5812/ cardiovascmed.30091

11. Komasi S, Saeidi M, Montazeri N, Masoumi M, Soroush A, Ezzati P. Which factors unexpectedly increase depressive symptom severity in patients at the end of a cardiac rehabilitation program? Ann Rehabil Med. 2015;39(6):872-879. https:// doi.org/10.5535/arm.2015.39.6.872

12. Singh A, Agrawal S, Gargya S, Saluja S, Kumar A, Kumar A, et al. Post-traumatic stress disorder after myocardial infarction and coronary artery bypass grafting. Int $J$ Crit Illn Inj Sci. 2017;7(2):84-90. https://doi.org/10.4103/ IJCIIS.IJCIIS_27_17

13. Komasi S, Soroush A, Khazaie H, Zakiei A, Saeidi M. Dreams content and emotional load in cardiac rehabilitation patients and their relation to anxiety and depression. Ann Card Anaesth. 2018;21:388-392. https://doi.org/10.4103/aca. ACA_210_17

14. Sandman N, Valli K, Kronholm E, Revonsuo A, Laatikainen T, Paunio T. Nightmares: risk factors among the Finnish general adult population. Sleep. 2015;38(4):507-514. https://doi. org/10.5665/sleep.4560

15. Asplund R. Nightmares, sleep and cardiac symptoms in the elderly. Neth $J$ Med. 2003;61(7):257-261. 
16. Pallant J. SPSS survival manual: a step by step guide to data analysis using SPSS for Windows (version 12). 2nd ed. Australia: Allen \& Unwin; 2005. pp 142-152.

17. Beck AT, Epstein N, Brown G, Steer RA. An inventory for measuring clinical anxiety: psychometric properties. $J$ Consult Clin Psychol. 1988;56(6):893-897. https://doi. org/10.1037/0022-006X.56.6.893

18. Ghassemzadeh H, Mojtabai R, Karamghadiri N, Ebrahimkhani N. Psychometric properties of a Persian-language version of the Beck depression inventory-second edition: BDI-II-PERSIAN. DepAnxiety. 2005;21(4):185-192. https://doi. org/10.1002/da.20070

19. Beck AT, Steer RA, Garbin MG. Psychometric properties of the Beck depression inventory: twenty-five years of evaluation. Clin Psych Rev. 1988;8:77-100. https://doi.org/10.1016/02727358(88)90050-5

20. Khesht-Masjedi MF, Omar Z, Masoleh SMK. Psychometrics properties of the Persian version of Beck anxiety inventory in North of Iranian adolescents. Int $J$ Education Psychol Res. 2015;1(2):145-153. https://doi. org/10.4103/2395-2296.152233

21. Buss AH, Perry MP. The aggression questionnaire. $J$ Personality Soc Psychol. 1992;63:452-459. https://doi.org/10.1037/0022$3514 \cdot 63 \cdot 3 \cdot 452$

22. Samani S. Study of reliability and validity of the Buss and Perry's aggression questionnaire. Iran $J$ Psychiatr Clin Psychol. 2008;13(4):359-365.

23. Schredl M. Characteristics and contents of dreams. Int Rev Neurobiol. 2010;92:135-154. https://doi.org/10.1016/Soo74-7742(10)92007-2

24. Schredl M, Burchert N, Gabatin Y. The effect of training on interrater reliability in dream content analysis. Sleep Hypnosis. 2004;6:139-144.

25. Malinowski JE, Horton CL. Metaphor and hyperassociativity: the imagination mechanisms behind emotion assimilation in sleep and dreaming. Front Psychol. 2015;6:1132. https://doi.org/10.3389/fpsyg.2015.01132

26. Curci A, Rimé B. Dreams, emotions, and social sharing of dreams. Cogn Emot. 2008;22(1):155-167. https://doi. org/10.1080/02699930701274102

27. Mehdipour-Rabori R, Abbaszadeh A, Borhani F. Human dignity of patients with cardiovascular disease admitted to hospitals of Kerman, Iran, in 2015. J Med Ethics Hist Med. 2016;9:8.
28. Bahremand M, Alikhani M, Zakiei A, Janjani P, Aghaei A. Emotion risk-factor in patients with cardiac diseases: the role of cognitive emotion regulation strategies, positive affect and negative affect (a case-control study). Global J Health Sci. 2016;8(1):173-179. https://doi.org/10.5539/gjhs. v8n1p173

29. Cartwright RD. Dreams that work: the relation of dream incorporation to adaptation to stressful events. Dreaming. 1991;1(1):3-9. https://doi. org/10.1037/hoog4312

30. Cartwright R, Newell P, Mercer P. Dream incorporation of a sentinel life event and its relation to waking adaptation. Sleep Hypnosis. 2001;3(1):25-32.

31. Weiner CL, Elkins M, Pincus D, Comer J. Anxiety sensitivity and sleep-related problems in anxious youth. J Anx Disord. 2015;32:66-72. https://doi. org/10.1016/j.janxdis.2015.03.009

32. Caska CM, Hendrickson BE, Wong MH, Ali S, Neylan T, Whooley MA. Anger expression and sleep quality in patients with coronary heart disease: findings from the heart and soul study. Psychosom Med. 2009;71(3):280-285. https://doi.org/10.1097/PSY.obo13e31819b6ao8

33. Cheung BMY, Au THY, Chan SY, Lam CM, Lau $\mathrm{SH}$, Lee $\mathrm{RP}$, et al. The relationship between hypertension and anxiety or depression in Hong Kong Chinese. Experiment Clin Cardiol. 2005;10(1):21-24.

34. Kani AS, Sunbul M, Kani HT, Yanartas O, Tezcan N, Emul M. Dream anxiety, chronotype and dipping pattern in hypertensive patients assessed with $24 \mathrm{~h}$ ambulatory blood pressure monitoring. Sleep Biol Rhy. 2016;14(1):23-30. https://doi. org/10.1007/s41105-015-0001-2

35. Player MS, Peterson LE. Anxiety disorders, hypertension, and cardiovascular risk: a review. Int $J$ Psychiatr Med. 2011;41(4):365-377. https://doi.org/10.2190/PM.41.4.f

36. Hosseini SH, Mokhberi V, Mohammadpour RA, Mehrabianfard M, Lashak NB. Anger expression and suppression among patients with essential hypertension. Int $J$ Psychiatr Clin Practice. 2011;15(3):214-218. https://doi.org/10.3109/136 51501.2011.572168

37. Armitage R, Rochlen A, Fitch T, Trivedi M, Rush AJ. Dream recall and major depression: a preliminary report. Dreaming. 1995;5(3):189198. https://doi.org/10.1037/hoo94434 
Original Article | Correlates of emotionally negative dreams

38. Rochlen A, Hoffmann R, Armitage R. EEG correlates of dream recall in depressed outpatients and healthy controls. Dreaming. 1998;8(2):109-123. https://doi.org/10.1023/ B:DREM.0000005901.68193.1f
39. Setia MS. Methodology series module 5: sampling strategies. Indian J Dermatol. 2016;61(5):505509. https://doi.org/10.4103/0019-5154.190118 